\title{
manejo de Plantas Daninhas em Maracujazeiro Amarelo Cultivado com Adubação Química e Orgânica ${ }^{1}$
}

\author{
Weed Management in Yellow Passion Fruit Cultivated with Chemical and Organic Fertilization
}

\author{
OGLIARI, J. ${ }^{2}$, FREITAS, S.P. ${ }^{3}$, CARVALHO, A.J.C. ${ }^{3}$, FERREIRA, L.R. ${ }^{4}$, MARINHO, C.S. ${ }^{3}$ e \\ THIEBAUT, J.T.L. ${ }^{5}$
}

\begin{abstract}
RESUMO - Objetivou-se, neste trabalho, avaliar diferentes formas de manejo de plantas daninhas na cultura do maracujazeiro, cultivado com adubação química e orgânica. O delineamento experimental foi em blocos casualizados, com 15 tratamentos, arranjados em esquema de parcelas subdivididas, com quatro repetições e 10 plantas úteis por parcela. Os tratamentos foram constituídos por três tipos de adubações na parcela (orgânica, química e química + orgânica) e cinco manejos de plantas daninhas na subparcela (com capina, sem capina, diuron (pré) + glyphosate (pós), diuron (pré) + MSMA (pós) e diuron (pré) + (diuron + paraquat) (pós). O diuron foi aplicado aos cinco dias antes do plantio das mudas, em todos os tratamentos com herbicida, variando apenas os herbicidas em pós-emergência; para cada um dos herbicidas das misturas avaliadas, foram feitas três aplicações, aos 45, 96 e 159 dias. O diuron em pré-emergência provocou sintomas de clorose nas folhas entre 20 e 26 dias após o plantio (DAP), sendo mais evidente no maracujazeiro cultivado com adubação química. Os tratamentos com diuron (pré) e glyphosate (pós) apresentaram melhor controle das plantas daninhas. Os tratamentos com adubação química + orgânica associados aos manejos com capina, diuron (pré) + glyphosate (pós) e diuron (pré) + (diuron + paraquat) (pós) foram os que proporcionaram maior produtividade de frutos. No cultivo com adubação orgânica, o tratamento capinado foi o que proporcionou maior produtividade. No cultivo com adubação química, a produtividade foi maior no tratamento com diuron (pré) + glyphosate (pós).
\end{abstract}

Palavras-chave: herbicida, Passiflora edulis, interferência, controle.

\begin{abstract}
The objective of this work was to evaluate different types of weed management in passion fruit culture under chemical and organic fertilization. The experimental design was in randomized blocks with 15 treatments, arranged in a splip-splot design, with four repetitions containing 10 plants each. The treatments consisted of three types of fertilization (organic, chemical and chemical + organic) and five types of weed management in each subplot (hand-hoeing, without hand-hoeing, diuron (pre-planting) + glyphosate (postemergence), diuron (pre-planting) $+M S M A$ (postemergence) and diuron (pre-planting) + (diuron + paraquat) (postemergence). Diuron applied in pre-planting induced phytotoxicity symptom in the leaves around 20 to 26 days after planting (DAP). However, it was more evident in plants undergoing chemical fertilization. The treatments with chemical + organic fertilization associated to hand-hoeing, diuron (pre-planting) + glyphosate (postemergence) and diuron (pre-planting) + (diuron + paraquat) (postemergence) provided the highest fruit productivity. For the cultivation using organic fertilization, hand-hoeing promoted the highest productivity. On the other hand, under, chemical fertilization, highest crop production and weed control were observed in the treatment diuron (pre) + glyphosate (post).
\end{abstract}

Keywords: herbicide, passion, fruit, interference, control.

1 Recebido para publicação em 20.11.2006 e na forma revisada em 25.10.2007.

2 Pós-Graduan do do Laboratório de Fitotecnia da Universidade Estadual do Norte Fluminense Darcy Ribeiro - UENF, Bolsista CNPq - Brasil, 28015-600, Campos dos Goytacazes, RJ, <juares@uenf.br>; ${ }^{3}$ Prof. associado do Laboratório de Fitotecnia, UENF; ${ }^{4}$ Prof. titular do Dep. de Fitotecnia da Universidade Federal de Viçosa - UFV, 36571-000 Viçosa, MG; ${ }^{5}$ Prof. associado do Laboratório de Engenharia Agrícola, UENF. 


\section{INTRODUÇÃO}

O maracujazeiro amarelo (Passiflora edulis) é originário do Brasil e amplamente cultivado em todo o território nacional. A produtividade média registrada em 2003 foi de 13,9 $\mathrm{t} \mathrm{ha}^{-1} \mathrm{ano}^{-1}$, sendo considerada baixa quando comparada com o potencial produtivo da cultura, que é superior a $50 \mathrm{t} \mathrm{ha}^{-1}$ ano $^{-1}$ (IBGE, 2006). A baixa produtividade pode ser influenciada por interferência das plantas daninhas, deficiência nutricional, ataque de pragas e doenças, estresse hídrico, baixa radiação solar, diminuição na temperatura ambiental, qualidade das mudas e deficiência de polinização (Simon \& Karnatz, 1983; Menzel et al., 1986).

A produtividade das plantas de maracujá pode ser incrementada pela adição de matéria orgânica, favorecendo a atividade biológica dos microrganismos e a capacidade de troca de cátions do solo (Zech et al., 1997). A matéria orgânica também promove a sorção de herbicida, atuando diretamente na imobilização e, com isso, reduzindo os danos à cultura (Czapar et al., 1994).

No maracujazeiro amarelo, o sistema radicular está concentrado aos $20 \mathrm{~cm}$ do solo, o que pode causar competição por nutrientes e água entre as plantas daninhas e a cultura, reduzindo consideravelmente a produtividade dos frutos (Souza et al., 2002). Devido à localização do sistema radicular, não é recomendada a capina, manual ou mecânica, pois ela pode danificar as raízes e facilitar a entrada de patógenos do solo.

Para controle das plantas daninhas no maracujazeiro, é aconselhável a utilização de herbicidas na linha de plantio e roçagem das entrelinhas para proteger o solo contra a erosão (Souza et al., 2002). Entretanto, trabalhos de pesquisa sobre a aplicação de herbicida na cultura do maracujazeiro são escassos e não existem, atualmente, produtos registrados pelo Ministério da Agricultura, Pecuária e Abastecimento (MAPA) para esse controle.

O objetivo deste trabalho foi avaliar o efeito de diferentes manejos de plantas daninhas associados à adubação química e/ou orgânica sobre a produtividade do maracujazeiro amarelo.

\section{MATERIAL E MÉTODOS}

O experimento foi conduzido entre $2001 \mathrm{e}$ 2002 na Estação Experimental do Centro de Ciências e Tecnologias Agropecuárias da Universidade Estadual do Norte Fluminense Darcy Ribeiro (UENF), em Campos dos GoytacazesRJ. O maracujazeiro foi cultivado em solo do tipo Argissolo Vermelho-Amarelo, apresentando as seguintes características: $\mathrm{pH}$ em água $(5,6), \mathrm{P}$ disponivel $\left(8,0 \mathrm{mg} \mathrm{dm}^{-3}\right), \mathrm{K}\left(50 \mathrm{mg} \mathrm{dm}^{-3}\right)$, $\mathrm{MO}\left(28,8 \mathrm{~g} \mathrm{dm}^{-3}\right)$, areia $\left(545 \mathrm{~g} \mathrm{~kg}^{-1}\right)$, silte $\left(76 \mathrm{~g} \mathrm{~kg}^{-1}\right)$ e argila (379 $\left.\mathrm{g} \mathrm{kg}^{-1}\right)$.

Foram avaliados três tipos de adubações (química + orgânica, orgânica e química) e cinco manejos de plantas daninhas (com capina, sem capina, diuron (pré) + glyphosate (pós), diuron (pré) + MSMA (pós) e diuron (pré) + (diuron + paraquat em pós-emergência). Utilizou-se o delineamento em blocos casualizados, com 15 tratamentos e quatro repetições, arranjados em esquema de parcelas subdivididas.

Em toda a área experimental foram aplicados $1.800 \mathrm{~kg} \mathrm{ha}^{-1}$ de calcário (PRNT 83\%) antes da aração e da gradagem e 0,12 kg na cova de plantio. O maracujazeiro foi cultivado no sistema de espaldeira vertical e irrigado com dois gotejadores por planta, com vazão individual de $8 \mathrm{~L} \mathrm{~h}^{-1}$.

As mudas foram plantadas em covas de $0,40 \mathrm{~m}$ de diâmetro por $0,50 \mathrm{~m}$ de profundidade e adubadas conforme os tratamentos: $50 \mathrm{~g}$ de micronutriente FTE-BR12 (composição por kg: 18 g de $\mathrm{B} ; 8,0$ g de $\mathrm{Cu}$; 30 g de Fe; 30 g de Mn; 1,0 g de Mo; e 90 g de $Z n$ ), 250 g de superfosfato simples, $50 \mathrm{~g}$ de cloreto de potássio no tratamento com adubação química e $20 \mathrm{~L}$ de esterco bovino na adubação orgânica e na adubação química + orgânica.

A adubação de cobertura constituiu-se de $510 \mathrm{~g}$ de sulfato de amônio e $475 \mathrm{~g}$ de cloreto de potássio, distribuídos em sete intervalos de 30 dias ao longo do experimento, em todos os tratamentos com a adubação química. Somente no tratamento com adubação orgânica foram aplicados na superficie do solo, a cada quatro meses, $10 \mathrm{~L}$ de esterco bovino em um raio de $0,50 \mathrm{~m}$ ao redor de cada planta.

A aplicação do diuron em pré-emergência foi efetuada cinco dias antes do plantio, e a 
dos demais herbicidas em pós-emergência, aos 45, 96 e 159 dias após o plantio (DAP), conforme a Tabela 1. A unidade experimental foi constituída por 12 plantas, espaçadas de 2,0 m entre elas e 3,0 m entre linhas, nas quais uma planta em cada extremidade foi considerada como bordadura.

Os herbicidas em pré e em pós-emergência foram aplicados em faixa de um metro, em cada lado da linha das plantas do maracujazeiro. As aplicações em pós-emergência foram dirigidas para que os herbicidas não atingissem o maracujazeiro. Foi utilizado um pulverizador costal manual com bico hidráulico de aço inoxidáveldo tipo leque (DG 8003), $\operatorname{com} 2 \mathrm{kgf} \mathrm{cm}^{-2}$ de pressão e consumo de $290 \mathrm{~L} \mathrm{ha}^{-1}$ de calda, equipado com chapéu-de-napoleão para as aplicações em pós-emergência. Em todos os tratamentos, as plantas daninhas presentes nas entrelinhas foram roçadas.

No momento da aplicação do diuron (pré), a temperatura do ar estava em torno de $22{ }^{\circ} \mathrm{C}$, a umidade relativa era de $64 \%$, a velocidade do vento, de $3,0 \mathrm{~km} \mathrm{~h}^{-1}$, e a radiação média, de $93 \mathrm{~W} \mathrm{~m}^{-1}$. Na aplicação dos herbicidas em pósemergência, a temperatura manteve-se em torno de $26{ }^{\circ} \mathrm{C}$, a umidade relativa do ar era de $67 \%$, a radiação solar, de $456 \mathrm{~W} \mathrm{~m}^{-2}$, e a velocidade do vento, de $2,7 \mathrm{~km} \mathrm{~h}^{-1}$.

Os sintomas de intoxicação nas plantas do maracujazeiro, provocados pelo diuron (pré), foram avaliados aos 20 e $26 \mathrm{DAP}$, propostos por Frans \& Talbert (1977). As plantas daninhas no tratamento sem capina e as não controladas pelo diuron (pré) foram quantificadas aos 42 DAP, utilizando-se quadrado de $0,50 \mathrm{~m}$ em quatro repetições por parcela. Após a contagem, elas foram secas em estufa a $70{ }^{\circ} \mathrm{C}$ por $72 \mathrm{~h}$, para determinação da massa seca.

As avaliações visuais do controle de plantas daninhas, pelos herbicidas aplicados em pós-emergência, foram realizadas 20 dias após a terceira aplicação (DAA), seguindo a escala proposta por Lorenzi (2000), em que $A=$ mais de $95 \%$ de controle, $\mathrm{S}=85$ a $95 \%$ de controle, $\mathrm{M}=50$ a $85 \%$ e $\mathrm{P}=$ menos de $50 \%$ de controle. A altura das plantas do maracujazeiro foi avaliada aos 60 e 90 DAP, com auxílio de uma régua graduada com precisão de um centímetro.

Os frutos foram classificados em A, B e C, de acordo com o tamanho. As dimensões de comprimento e diâmetro de cada classe foram de: $>84 \mathrm{~mm}$ e $>69 \mathrm{~mm} ; 73-83 \mathrm{~mm}$ e $63-$ $68 \mathrm{~mm}$; e $\leq 72 \mathrm{~mm} \mathrm{e} \leq 62 \mathrm{~mm}$, respectivamente.

Todos os dados, exceto os de controle de plantas daninhas em pós-emergência, foram submetidos à análise de variância pelo teste $\mathrm{F}$, e as médias, comparadas pelo teste de Tukey (5\%).

\section{RESULTADOS E DISCUSSÃO}

\section{Sintomas de intoxicação e controle de plantas daninhas}

Em todos os tratamentos com diuron (pré), observou-se clorose nas folhas entre 20 e 26 DAP (Tabela 2). Entretanto, após 26 DAP as folhas novas não apresentaram sintomas de intoxicação, e as folhas velhas com clorose soltaram-se da planta. Em trabalhos com canade-açúcar tratada com diuron ${ }^{14} \mathrm{C}$, Musumeci

Tabela 1 - Manejo de plantas daninhas utilizado

\begin{tabular}{|c|c|c|c|c|}
\hline \multirow{2}{*}{ Tratamentos } & \multirow{2}{*}{$\begin{array}{c}\text { Em pré-emergência } \\
\left(\mathrm{kg} \mathrm{ha}^{-1}\right)\end{array}$} & \multicolumn{3}{|c|}{ Em pós-emergência $\left(\mathrm{kg} \mathrm{ha}^{-1}\right)$} \\
\hline & & 45 DAP & 96 DAP & $159 \mathrm{DAP}$ \\
\hline Testemunha com capina & - & - & - & - \\
\hline Testemunha sem capina & - & - & - & - \\
\hline Diuron (pré) $)^{1 /}+$ glyphosate (pós) $)^{2 /}$ & 3,0 & 1,08 & 1,08 & 1,08 \\
\hline Diuron $(\text { pré })^{1 /}+$ MSMA (pós) $)^{3 /}$ & 3,0 & 2,40 & 2,40 & 2,40 \\
\hline Diuron (pré) $)^{\frac{1}{\prime}}+(\text { diuron }+ \text { paraquat) (pós })^{4 /}$ & 3,0 & 0,90 & 0,90 & 0,90 \\
\hline
\end{tabular}

Médias seguidas de mesma letra na coluna não diferem entre si pelo teste de Tukey a $5 \%$ de probabilidade. $\mathrm{CV}(\mathrm{A})=16,57 ; \mathrm{CV}(\mathrm{B})=$ 21,86 e CV $(C)=14,72$.

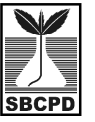


Tabela 2 - Porcentagem de clorose nas folhas do maracujazeiro amarelo provocada pelo diuron (pré) aos 20 e 26 dias após plantio (DAP), associado a diferentes adubações

\begin{tabular}{|c|c|c|c|c|}
\hline \multirow{2}{*}{} & \multicolumn{3}{|c|}{ Tipos de adubação } & \multirow{2}{*}{ Média } \\
\cline { 2 - 5 } & Química + Orgânica & Orgânica & Química & 29,7 \\
\hline 20 DAP & $26,6 \mathrm{~b}$ & $28,1 \mathrm{~b}$ & $34,5 \mathrm{a}$ & 25,2 \\
\hline 26 DAP & $23,1 \mathrm{~b}$ & $23,4 \mathrm{~b}$ & $29,0 \mathrm{a}$ & 2 \\
\hline
\end{tabular}

Médias seguidas pela mesma letra na linha não diferem entre si pelo teste Tukey a $5 \%$ de probabilidade. CV $(20 \mathrm{DAP})=21,05$. CV $(20 \mathrm{DAP})=27,30 . \mathrm{DAP}=$ dias após o plantio.

et al. (1995) observaram que os sintomas de clorose aumentaram em quatro semanas após a emergência da cultura.

A análise de variância para o percentual de clorose nas folhas do maracujazeiro foi significativa, em função do diuron em pré-emergência, quando associado aos tipos de adubação. A clorose promovida pelo diuron (pré), quando associado à adubação química, foi maior quando comparada à adubação orgânica e química + orgânica, nas duas épocas avaliadas (Tabela 2). Essa menor porcentagem de clorose causada pelo diuron (pré) nos tratamentos com adubações orgânica e química + orgânica pode estar relacionada à inativação do diuron pela matéria orgânica. Liu et al. (1970), ao estudarem a adsorção do diuron, constataram que o comportamento sortivo do herbicida estava correlacionado ao teor de matéria orgânica e à capacidade de troca cationica (CTC) dos solos. Freitas et al. (1998) verificaram que a adsorção do diuron aumentou linearmente, atingindo um pico de $37,5 \%$ quando adicionados ao solo $90 \mathrm{t} \mathrm{ha}^{-1}$ de composto orgânico, proveniente de resíduo de suinocultura.

Comparando a testemunha sem capina e o tratamento com diuron (pré), observou-se que este promoveu redução de $73,63 \%$ no número de plantas daninhas e $87 \%$ na massa seca (Tabela 3). Martins et al. (1997) verificaram, na cultura da videira, que o diuron (pré) a $2,0 \mathrm{~kg} \mathrm{ha}^{-1}$ foi seletivo e eficiente no controle de Digitaria horizontalis (capim-colchão), Amaranthus hibridus (caruru), Sida rhombifolia (guanxuma) e Bidens pilosa (picão-preto).

Em relação à altura das plantas do maracujazeiro, não foram verificadas diferenças entre os tratamentos (capina, sem capina e os herbicidas em pré e pós-emergência) aos 60 DAP (Tabela 4), indicando que a clorose nas folhas,
Tabela 3 - Eficiência do diuron sobre o número total e da massa seca das plantas daninhas na cultura do maracujazeiro, em relação ao tratamento sem capina

\begin{tabular}{|l|c|c|}
\hline & Sem capina & Com diuron \\
\hline $\begin{array}{l}\text { Número de plantas } \\
\text { daninhas }\left(\mathrm{m}^{-2}\right)\end{array}$ & 110 & 29 \\
\hline Massa seca $\left(\mathrm{g} \mathrm{m}^{-2}\right)$ & 102 & 13 \\
\hline
\end{tabular}

provocada pelo diuron (pré), não interferiu no crescimento das plantas. Esse comportamento também foi observado por Lima et al. (1999) em maracujazeiro cultivado em vaso por 45 dias, no qual a altura média das plantas não foi afetada na dose de diuron até $4,8 \mathrm{~kg} \mathrm{ha}^{-1}$. No presente trabalho, observou-se, entretanto, que, aos 90 DAP, a altura do maracujazeiro foi menor no tratamento sem capina em relação aos demais tratamentos, no qual as plantas daninhas atingiram altura superior à do maracujazeiro (Tabela 4).

As espécies de plantas daninhas que predominaram no experimento foram Panicum maximum (capim-colonião), Indigofera hirsuta (anil-roxo), Sida rhombifolia (guanxuma), Digitaria horizontalis (capim-colchão) e Emilia sonchifolia (falsa-serralha). Panicum maximum foi a espécie de maior expressão na área, promovendo elevado sombreamento para o maracujazeiro. Esta espécie foi altamente suscetivel ao tratamento com diuron (pré) + três aplicações de glyphosate (pós), resultando em controle superior a $95 \%$ (Tabela 5 ).

O controle de $P$. maximum, no tratamento com diuron (pré) + (diuron + paraquat em pósemergência), foi superior a $95 \%$ somente em plantas com estádio até quatro perfilhos nas três aplicações. Nos tratamentos com diuron (pré) + MSMA (pós), o controle foi inferior a $50 \%$. 
Tabela 4 - Altura média (m) das plantas do maracujazeiro aos 60 e 90 dias após plantio (DAP), nos diferentes manejos de plantas daninhas

\begin{tabular}{|l|c|c|c|c|c|}
\hline & $\begin{array}{c}\text { Testemunha } \\
\text { capinada }\end{array}$ & $\begin{array}{c}\text { Testemunha } \\
\text { sem capina }\end{array}$ & $\begin{array}{c}\text { Diuron (pré) }+ \\
\text { glyphosate (pós) }\end{array}$ & $\begin{array}{c}\text { Diuron (pré) + } \\
\text { MSMA (pós) }\end{array}$ & $\begin{array}{c}\text { Diuron (pré) + (diuron } \\
+ \text { paraquat) (pós) }\end{array}$ \\
\hline 60 DAP & $1,02 \mathrm{a}$ & $0,92 \mathrm{a}$ & $0,92 \mathrm{a}$ & $0,91 \mathrm{a}$ & $1,04 \mathrm{a}$ \\
\hline 90 DAP & $1,86 \mathrm{a}$ & $1,56 \mathrm{~b}$ & $1,76 \mathrm{a} \mathrm{b}$ & $1,81 \mathrm{a} \mathrm{b}$ & $1,90 \mathrm{a}$ \\
\hline
\end{tabular}

Médias seguidas de mesma letra em cada época não diferem entre si pelo teste de Tukey a 5\% de probabilidade. CV=11,46.

Tabela 5 - Controle das plantas daninhas aos 20 dias após a terceira aplicação de herbicidas em pós-emergência na cultura do maracujazeiro

\begin{tabular}{|c|c|c|c|}
\hline \multirow{2}{*}{ Plantas daninhas } & Glyphosate & MSMA & Diuron + Paraquat \\
\hline & \multicolumn{3}{|c|}{----------------------------------------------------" \% ---------------------------------------------------- } \\
\hline Panicum maximum & 95 & 50 & $95^{*}$ \\
\hline Indigofera hirsuta & $95 *$ & 0 & $95 *$ \\
\hline Sida rhombifolia & 95 & 0 & $95 *$ \\
\hline Digitaria horizontalis & 95 & 50 & 95 \\
\hline Emilia sonchifolia & 95 & 0 & 95 \\
\hline
\end{tabular}

* Secamento das plantas mais desenvolvidas (somente as folhas e os ramos novos), com posterior desenvolvimento de novas folhas e ramos, exceto nas espécies Panicum maximum e Digitaria horizontalis, em que as folhas secaram, mas as gemas basais não foram danificadas.

As plantas da espécie Indigofera hirsuta, com estádio de até quatro pares de folhas, foram altamente suscetiveis ao tratamento com diuron (pré) + glyphosate (pós) e diuron (pré) + (diuron + paraquat em pós-emergência), resultando em controle superior a 95\%. Todavia, nas plantas mais desenvolvidas, esse tratamento não foi eficiente. Esta espécie apresentou tolerância ao tratamento com diuron (pré) + MSMA (pós) (Tabela 5).

Sida rhombifolia foi suscetivel ao diuron (pré) + glyphosate em pós-emergência, sendo seu controle superior a $95 \%$ neste tratamento. No entanto, no tratamento com diuron (pré) + (diuron + paraquat em pós-emergência), essa planta foi suscetivel apenas no estádio inicial de desenvolvimento. O tratamento com diuron (pré) + MSMA (pós) não foi eficiente no controle da S. rhombifolia (Tabela 5).

O controle da planta daninha Digitaria horizontalis nos tratamentos com diuron (pré) + glyphosate (pós) e diuron (pré) + (diuron + paraquat em pós-emergência) foo superior a $95 \%$. No tratamento com diuron (pré) + MSMA (pós) o controle foi inferior a $50 \%$ (Tabela 5).
Emilia sonchifolia foi suscetivel ao diuron (pré) + glyphosate (pós) e diuron (pré) + (diuron + paraquat) em pós-emergência (controle superior a 95\%) e tolerante ao diuron (pré) + MSMA (pós) (Tabela 5).

A presença das espécies de plantas daninhas na testemunha sem capina resultou em morte de aproximadamente $82 \%$ do maracujazeiro, ocasionando redução de $97 \%$ na produtividade dos frutos em comparação ao tratamento com capina (Tabela 6). Além disso, durante a colheita, as plantas daninhas dificultaram a visualização dos frutos caídos no solo.

\section{Produtividade e classificação de frutos}

A produtividade das plantas foi influenciada pela interação entre o manejo de plantas daninhas e o tipo de adubação, sendo as respectivas médias apresentadas na Tabela 6. Os tratamentos com capina, diuron (pré) + glyphosate (pós) e diuron (pré) + (diuron + paraquat em pós-emergência) associados à adubação química + orgânica foram os que proporcionaram maior produtividade de frutos. Contudo, a maior produtividade de frutos com adubação 
Tabela 6 - Produção de frutos $\left(\mathrm{t} \mathrm{ha}^{-1}\right)$ do maracujazeiro amarelo em relação ao manejo de plantas daninhas (MPD) e tipo de adubação

\begin{tabular}{|l|c|c|c|c|c|c|}
\hline Tratamentos & Capinado & Sem capina & $\begin{array}{c}\text { Diuron (pré) }+ \\
\text { glyphosate } \\
\text { (pós) }\end{array}$ & $\begin{array}{c}\text { Diuron (pré) + } \\
\text { MSMA } \\
\text { (pós) }\end{array}$ & $\begin{array}{c}\text { Diuron (pré) }+ \\
\text { (diuron }+ \\
\text { paraquat) (pós) }\end{array}$ & $\begin{array}{c}\text { Mćdia } \\
\text { Química + orgânica }\end{array}$ \\
\hline Orgânica & $23,3 \mathrm{aB}$ & $0,77 \mathrm{cA}$ & $23,6 \mathrm{aA}$ & $20,4 \mathrm{bB}$ & $23,7 \mathrm{aA}$ & 18,3 \\
\hline Química & $25,1 \mathrm{aA}$ & $0,74 \mathrm{eA}$ & $24,0 \mathrm{bA}$ & $21,1 \mathrm{dA}$ & $22,4 \mathrm{bB}$ & 17,4 \\
\hline Média & 23,9 & 0,75 & 23,2 & 20,0 & 22,9 & 18,7 \\
\hline
\end{tabular}

Médias seguidas da mesma letra, minúscula na linha e maiúscula na coluna, não diferem entre si pelo teste de Tukey a $5 \%$ de probabilidade. $\mathrm{CV}($ adubação $)=1,31$ e $\mathrm{CV}($ manejo $)=1,52$.

química foi observada na testemunha com capina.

O peso médio dos frutos foi influenciado pela interação entre o manejo de plantas daninhas e o tipo de adubação, sendo maior na adubação química + orgânica associada ao manejo com capina, diuron (pré) + MSMA (pós) e diuron (pré) + (diuron + paraquat em pós-emergência) (Tabela 7).

Na adubação orgânica, os tratamentos capinado, diuron (pré) + (diuron + paraquat) (pós) e diuron (pré) + glyphosate (pós) proporcionaram frutos com maiores pesos. Nesse tipo de adubação, o tratamento sem capina foi o que resultou em frutos de menor peso. O peso médio dos frutos, entre os diferentes tratamentos, variou de 129 a 193 g. Borges et al. (2003) obtiveram peso médio dos frutos de $93 \mathrm{~g}$, com produtividade média de $26 \mathrm{t} \mathrm{ha}^{-1}$. Carvalho et al. (2000) obtiveram peso médio dos frutos de $161 \mathrm{~g}$, com produtividade média de 41,3 $\mathrm{t} \mathrm{ha}^{-1}$.

A produção de frutos classe A não foi afetada pela interação entre tipo de adubação e manejo de plantas daninhas. $O$ tratamento sem capina produziu menor percentual de frutos de classe A em relação aos demais tratamentos (Tabela 8).

Os diferentes tipos de adubação não influenciaram as porcentagens de frutos das classes A e B. Entretanto, na classe C, o tamanho dos frutos foi alterado pelos diferentes tipos de adubação, sendo a adubação química responsável pela produção de maior porcentagem de frutos de menor tamanho (Tabela 9).

Conclui-se que a produtividade de frutos do maracujazeiro amarelo foi maior nos tratamentos com adubação química + orgânica associados ao manejo de plantas daninhas por capina e a aplicações de diuron (pré) + glyphosate (pós) ou diuron (pré) + (diuron + paraquat em pós-emergência). Quando se aplica apenas a adubação orgânica, o melhor manejo é o capinado, e quando se emprega apenas a adubação química, o manejo de plantas daninhas por capina ou pela aplicação do diuron (pré) + glyphosate (pós) é melhor. O controle de plantas daninhas é melhor com os herbicidas diuron (pré) e glyphosate (pós). No tratamento sem capina, as plantas daninhas provocaram decréscimo na produtividade de frutos, independentemente do tipo de adubação empregado.

Tabela 7 - Peso médio (g) de frutos do maracujazeiro amarelo em relação ao manejo de plantas daninhas e tipo de adubação

\begin{tabular}{|l|l|l|c|c|c|c|}
\hline \multicolumn{1}{|c|}{ Tratamentos } & Capinado & Sem capina & $\begin{array}{c}\text { Diuron (pré) + } \\
\text { glyphosate (pós) }\end{array}$ & $\begin{array}{c}\text { Diuron (pré) + } \\
\text { MSMA (pós) }\end{array}$ & $\begin{array}{c}\text { Diuron (pré) + } \\
\text { (diuron + paraquat) }\end{array}$ & Média \\
\hline Química + orgânica & $186 \mathrm{abA}$ & $153 \mathrm{cA}$ & $178 \mathrm{bAB}$ & $186 \mathrm{abA}$ & $193 \mathrm{aA}$ & 179 \\
\hline Orgânica & $181 \mathrm{abAB}$ & $129 \mathrm{cB}$ & $187 \mathrm{aA}$ & $173 \mathrm{bB}$ & $178 \mathrm{abB}$ & 170 \\
\hline Química & $175 \mathrm{abB}$ & $136 \mathrm{cB}$ & $173 \mathrm{bB}$ & $186 \mathrm{aA}$ & $178 \mathrm{abB}$ & 169 \\
\hline Média & 181 & 139 & 179 & 181 & 183 & 173 \\
\hline
\end{tabular}

Médias seguidas da mesma letra, minúscula na linha e maiúscula na coluna, não diferem entre si pelo teste de Tukey a $5 \%$ de probabilidade. $\mathrm{CV}($ adubação $)=4,82$ e CV $($ manejo $)=3,14$. 
Tabela 8 - Classificação dos frutos do maracujazeiro amarelo de acordo com o tamanho, em diferentes manejos de plantas daninhas

\begin{tabular}{|l|c|c|c|}
\hline \multicolumn{1}{|c|}{ Manejo de plantas daninhas } & Classe A (\%) & Classe B (\%) & Classe C (\%) \\
\hline Capinado & $51,4 \mathrm{a}$ & $21,3 \mathrm{a}$ & $27,3 \mathrm{a}$ \\
\hline Sem capina & $43,4 \mathrm{~b}$ & $23,8 \mathrm{a}$ & $32,3 \mathrm{a}$ \\
\hline Diuron (pré) + glyphosate (pós) & $50,0 \mathrm{a}$ & $22,6 \mathrm{a}$ & $27,4 \mathrm{a}$ \\
\hline Diuron (pré) + MSMA (pós) & $51,7 \mathrm{a}$ & $21,5 \mathrm{a}$ & $26,8 \mathrm{a}$ \\
\hline Diuron (pré) + (diuron + paraquat em pós-emergência) & $52,7 \mathrm{a}$ & $21,6 \mathrm{a}$ & $25,7 \mathrm{a}$ \\
\hline Médias & 49,9 & 22,2 & 27,8 \\
\hline
\end{tabular}

Médias seguidas da mesma letra na coluna não diferem entre si pelo teste de Tukey a $5 \%$ de probabilidade. $\mathrm{CV}(\mathrm{A})=11,21, \mathrm{CV}(\mathrm{B})=$ 24,41 e $\mathrm{CV}(\mathrm{C})=24,65$.

Tabela 9 - Classificação dos frutos do maracujazeiro amarelo, em porcentagem, de acordo com diferentes tipos de adubação

\begin{tabular}{|l|c|c|c|}
\hline \multicolumn{1}{|c|}{ Tipos de adubação } & Classe A (\%) & Classe B (\%) & Classe C (\%) \\
\hline Química + orgânica & $52,0 \mathrm{a}$ & $22,6 \mathrm{a}$ & $25,4 \mathrm{~b}$ \\
\hline Orgânica & $48,9 \mathrm{a}$ & $23,3 \mathrm{a}$ & $27,8 \mathrm{ab}$ \\
\hline Química & $47,6 \mathrm{a}$ & $22,4 \mathrm{a}$ & $30,0 \mathrm{a}$ \\
\hline Médias & 49,5 & 22,8 & 27,7 \\
\hline
\end{tabular}

Médias seguidas de mesma letra na coluna não diferem entre si pelo teste de Tukey a $5 \%$ de probabilidade. $\mathrm{CV}(\mathrm{A})=16,57, \mathrm{CV}(\mathrm{B})=$ 21,86 e $\mathrm{CV}(\mathrm{C})=14,72$.

\section{AGRADECIMENTOS}

Ao CNPq, pela concessão da bolsa, e à Faperj, pelo apoio financeiro no desenvolvimento do projeto.

\section{LITERATURA CITADA}

BORGES, A. L. et al. Produtividade e qualidade do maracujazeiro-amarelo irrigado, adubado com nitrogênio e potássio. R. Bras. Frutic., v. 25, n. 2, p. 259-262, 2003.

CARVALHO, A. J. C. et al. Adubação nitrogenada e irrigação no maracujazeiro amarelo-1: produtividade e qualidade dos frutos. Pesq. Agropec. Bras., v. 35, n. 6, p. 1101-1108, 2000.

CZAPAR, G. F.; KANVAR, R. S.; FAWCETT, R. Herbicide and trace movement to field drainage tiles under simulated rainfall conditions. Soil Till. Res., v. 30, n. 1, p.19-32, 1994.

FRANS, R. E.; TALBERT, R. E. Design of fiel experimentes and the measurement and analisis of plant responses. In: TRUELOVE, B. (Ed.). Research methods in weed science. Fayetheville, Arkansas: Southern Weed Science Society, p. 16-23, 1977.
FREITAS, S. P. et al. Efeito de resíduos da suinocultura sobre a atividade do diuron aplicado ao solo. R. Ceres, v. 45, p. 491-504, 1998.

INSTITUTO BRASILEIRO DE GEOGRAFIA E ESTATÍSTICA - IBGE. Produção agrícola municipal. <http://www.sidra.ibge.gov.br>. Acesso em: 12 dez. 2006.

LIMA, A. A.; CARVALHO, J. E. B.; CALDAS, R. C. Seletividade de herbicidas aplicados em pré-emergência para mudas de maracujá amarelo. R. Bras. Frutic., v. 21, n. 3, p. $379-381,1999$.

LIU, L. C.; CIBES-VIADÉ, H.; KOO, F. K. S. Adsorption of ametryne and diuron by soils. Weed Sci., v. 18, p. 470474, 1970.

LORENZI, H. Manual de identificação e controle de plantas daninhas; plantio direto e convencional. 5. ed. Nova Odessa: Plantarum, 2000. p. 339.

MARTINS, P. E. et al. Controle químico e cultural das plantas daninhas na videira Niagara rosada. R. Bragantia, v. 56, n. 1, p. 135-143, 1997.

MENZEL, C. M.; SIMPSON, O. R.; DOWLING, A. J. Water relations in Passion fruit: effect of moisture stress on growth, flowering and nutrient uptake. Sci. Hortic., v. 29, p. 239-349, 1986. 
MUSUMECI, M. R. et al. Degradação do diuron ${ }^{-14} \mathrm{C}$ em solo e em plantas de cana-de-açúcar (Saccharum spp.). Pesq.

Agropec. Bras., v. 30, n. 6, p. 775-778, 1995.

SIMON, P.; KARNATZ, A. Effect of soil and air temperature on growth and flower formation of purple passion fruit (Passiflora edulis). Acta Hortic., v. 139, p. 120-128, 1983.
SOUSA, V. F. et al. Distribuição radicular do maracujazeiro sob diferentes doses de potássio aplicadas por fertirrigação. R. Bras. Eng. Agríc. Amb., v. 6, n. 1, p. 51-56, 2002.

$\mathrm{ZECH}, \mathrm{W}$. et al. Factor controlling humification and mineralization of soil organic matter in the tropics.

Geoderma, v. 79, p. 117-161, 1997. 